\title{
Agbio keeps on growing
}

Stacy Lawrence

In 2004, global acreage of transgenic crops grew by one-fifth to more than 80 million hectares, valued at almost $\$ 5$ billion. The top $>$ transgenic crop continues to be soybeans (more than half of area planted with soybeans is transgenic) with maize, corn and cotton

\section{Global area of transgenic crops by country}

Relative newcomers Brazil, China, India and South Africa increased transgenic planting substantially last year.

\section{Total GM crop area}

(million hectares)

47.6
16.2
5.4
5.0
3.7
1.2
0.5
0.5
0.3
0.2

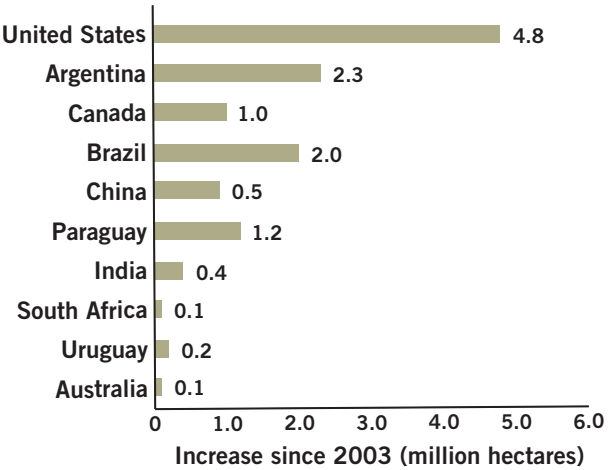

Source: International Service for the Acquisition of Agri-Biotech Applications

\section{Historical global area of biotech crops}

The area of land planted with biotech plants has almost doubled since 2000 , as has the value of those crops.

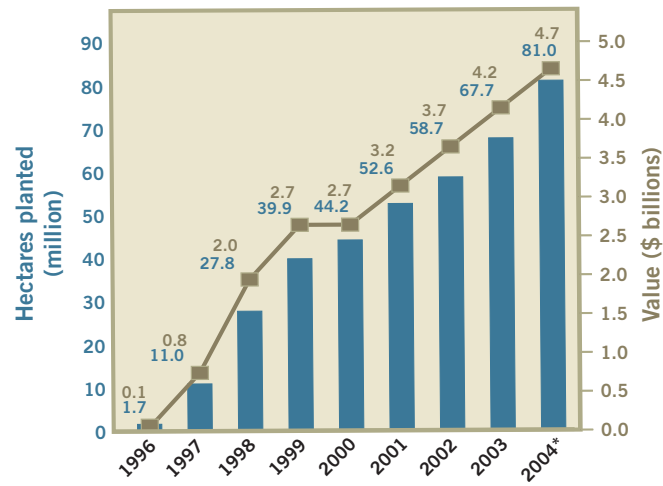

*Projection. Source: Cropnosis, International Service for the Acquisition of Agri-Biotech Applications

Global area by transgenic trait

\begin{tabular}{lcccc}
\hline & $\begin{array}{c}\text { Transgenic crop } \\
\text { area (million } \\
\text { hectares) }\end{array}$ & $\begin{array}{c}\text { Increase since } \\
2003 \text { (million } \\
\text { hectares) }\end{array}$ & $\begin{array}{c}\text { Percent } \\
\text { increase }\end{array}$ & $\begin{array}{c}\text { Percent of total biotech } \\
\text { crops }\end{array}$ \\
\hline Herbicide tolerance & 58.6 & 8.9 & $72 \%$ & $72 \%$ \\
Insect resistance (Bt) & 15.6 & 3.4 & $19 \%$ & $20 \%$ \\
Bt/Herbicide tolerance & 6.8 & 1 & $9 \%$ & $8 \%$ \\
Virus resistance/Other & $<0.1$ & $<0.1$ & $<1 \%$ & - \\
\hline
\end{tabular}

Source: International Service for the Acquisition of Agri-Biotech Applications having about $15 \%$ and $30 \%$, respectively, of total area planted with transgenic seeds. The United States is by far the largest producer (57\% of worldwide area planted) followed by Argentina, Canada, Brazil and China.

\section{US field trials approved in $\mathbf{2 0 0 4}$}

Field trials were initiated for a total of 55 different transgenic crops in 2004 , mostly in corn but also in alfalfa, wheat and certain tree species.

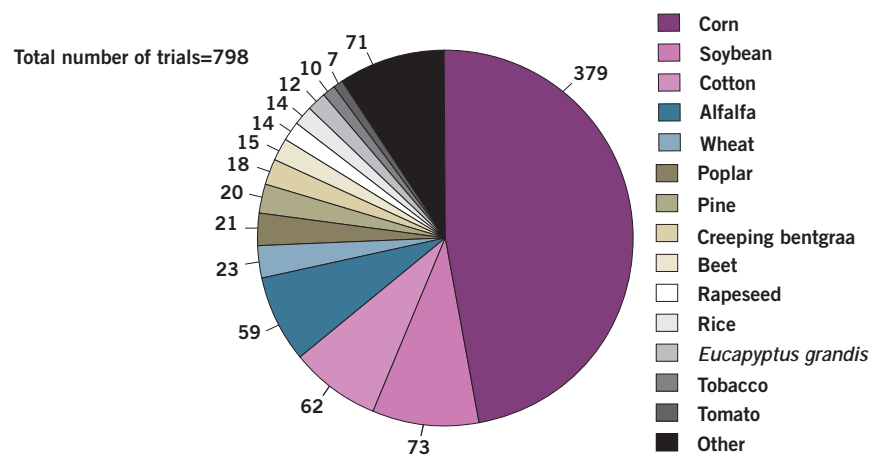

Source: Economic Research Service of the United States Department of Agriculture

Top 10 transgenic plant patent holders at USPTO

\begin{tabular}{lcc}
\hline Rank & Entity & Utility patents held \\
\hline 1 & Monsanto (St. Louis, MO, USA) & 674 \\
2 & Du Pont (Wilmington, DE, USA) & 565 \\
3 & Pioneer Hi-bred (Des Moines, lowa) & 449 \\
4 & US Department of Agriculture (Washington, DC, USA) & 315 \\
5 & Syngenta (Basal, Switzerland) & 284 \\
6 & Novartis (Basel, Switzerland) & 230 \\
7 & University of California System & 221 \\
8 & BASF (Ludwigshafen, Germany) & 217 \\
9 & Dow Chemical (Midland, Michigan, USA) & 214 \\
10 & Hoechst Japan (Frankfurt, Germany) & 207 \\
*Including subsidiaries. Data as of May 2004. Source: Economic Research Service of the \\
United States Department of Agriculture
\end{tabular}

\begin{tabular}{lcccc} 
Global area of transgenic crop & & \\
\hline $\begin{array}{c}\text { Transgenic crop area } \\
\text { (million hectares) }\end{array}$ & $\begin{array}{c}\text { Increase since 2003 } \\
\text { (million hectares) }\end{array}$ & Percent increase & $\begin{array}{c}\text { Biotech area } \\
\text { as a percent of } \\
\text { total crop }\end{array}$ \\
\hline Soybean & 48.4 & 7 & $60 \%$ & $56 \%$ \\
Maize & 19.3 & 3.8 & $23 \%$ & $14 \%$ \\
Cotton & 9 & 1.8 & $11 \%$ & $28 \%$ \\
Canola & 4.3 & 0.7 & $6 \%$ & $19 \%$ \\
Squash & $<0.1$ & - & $<1 \%$ & - \\
Papaya & $<0.1$ & - & $<1 \%$ & - \\
\hline
\end{tabular}

Source: International Service for the Acquisition of Agri-Biotech Applications 